\title{
APLIKASI GLOBAL POSITIONING SYSTEM (GPS) DAN CO-TIDAL UNTUK PENGAMATAN NILAI TINGGI MUKA AIR LAUT DI PERAIRAN LAUT JAWA
}

\author{
Khomsin ${ }^{1}$, Khariz Syaputra², Danar Guruh Pratomo ${ }^{3}$ \\ Departemen Teknik Geomatika, FTSLK-ITS, Kampus ITS Sukolilo, Surabaya, 60111, Indonesia \\ e-mail: ${ }^{1}$ khomsin@geodesy.its.ac.id, ${ }^{2}$ kharizsya10@gmail.com, ${ }^{3}$ guruh@geodesy.its.ac.id
}

\begin{abstract}
Abstrak
Pasang surut air laut (pasut) merupakan salah satu komponen penting dalam survei batimetri. Pada survei batimetri, pengamatan pasut dilakukan dengan menggunakan rambu pasut di pinggir pantai. Seiring berkembangnya teknologi, penggunaan Global Positioning System (GPS) semakin memungkinkan dalam survei batimetri. Selain dalam penentuan posisi horizontal, GPS juga dapat digunakan untuk menentukan posisi vertikal. Namun, karakteristik pasut yang berbeda-beda di setiap lokasi menyebabkan nilai pasut tersebut tidak valid jika digunakan dilokasi yang berjauhan. Di kawasan seperti di lepas pantai, karakteristik pasut biasanya ditentukan secara tidak langsung dengan melakukan prediksi menggunakan co-tidal chart. Dalam penelitian ini, dilakukan perbandingan tingkat akurasi nilai tinggi muka air laut hasil dari GPS dan hasil dari co-tidal terhadap hasil dari rambu pasut. Uji tingkat akurasi yang dilakukan menggunakan perhitungan RMSE. Dimana, nilai RMSE antara data hasil rambu pasut dan GPS pada tanggal 26, 27, dan 28 April 2018 sebesar 0,246 meter, 0,061 meter, dan 0,051 meter. Sedangkan, pada perbandingan nilai tinggi muka air laut hasil rambu pasut dan hasil co-tidal, nilai RMSE pada tanggal 26, 27, dan 28 April 2018 sebesar 0,237 meter, 0,286 meter, dan 0,109 meter.
\end{abstract}

Kata kunci: Co-tidal Chart, Global Positioning System (GPS), Tinggi Muka Air Laut.

\begin{abstract}
Tides is one of the important components in the bathymetry survey. Usually, tides observations made using conventional tide gauge. Along with the development of technology, Global Positioning System (GPS) is often used in bathymetry survey. Besides in horizontal positioning, GPS can also be used to determine the vertical position. However, the tide's characteristic different in each location causes the value of the tide is invalid if used in a different location. In areas such as offshore, the tide's characteristic is usually determined indirectly by making predictions using co-tidal chart. In this study, a comparison will be made of sea water level value results of GPS and the result of co-tidal against the results of observations of conventional tide gauge. The comparison test is performed using the calculation of RMSE for 3 day time observations. The results of this research show that the value of the RMSE for 3 days between conventional tide gauge observations data and GPS observations data on 26, 27, and 28 April 2018 is 0.251, 0.068, and 0.080 meter. Whereas, in the comparison between conventional tide gauge observatrions data and co-tidal data, the RMSE values on 26, 27, and 28 April 2018 is $0.204,0.234$, and 0.081 meter.
\end{abstract}

Keywords: Co-tidal Chart, Global Positioning System (GPS), Sea Water Level. 


\section{PENDAHULUAN}

Pasang surut air laut adalah suatu fenomena alam yaitu naik-turunnya permukaan air laut secara periodik sebagai akibat dari adanya gaya gravitasi benda-benda langit terutama bulan dan matahari. Pengaruh benda astronomi lainnya dapat diabaikan karena jarak dan ukurannya yang relatif lebih kecil daripada bulan dan matahari. Pasut di perairan semi tertutup seperti teluk dipengaruhi oleh faktor non astronomi yaitu berupa bentuk garis pantai dan topografi dasar perairan (Stewart 2008) .

Pengamatan pasut pada umumnya dilakukan di pinggir pantai atau dermaga/pelabuhan dengan menggunakan rambu pasut atau peralatan tide gauge lainnya. Karakteristik pasut yang diamati di tepi pantai atau dermaga/pelabuhan umumnya hanya valid untuk kawasan dengan radius tertentu dari titik pengamatan. Di luar kawasan tersebut, seperti dilepas pantai, karakteristik pasut biasanya ditentukan secara tidak langsung, yaitu dengan melakukan prediksi menggunakan co-tidal chart (Abidin 2007).

Pengamatan pasut dilakukan dengan tujuan untuk mencatat atau merekam gerakan vertikal permukaan air laut yang terjadi secara periodik. Data hasil pengamatan pasut tersebut dapat digunakan untuk koreksi kedalaman hasil pemeruman. Pengamatan pasut yang dilakukan terkadang berjauhan dengan lokasi pemeruman. Sehingga ada kemungkinan data pasut tidak valid jika digunakan untuk koreksi hasil pemeruman. Hal tersebut dikarenakan karakteristik pasang surut air laut dapat berbeda antara satu daerah dengan daerah lainnya (Haryono dan Narni 2004).

Penggunaan Global Positioning System (GPS) dapat digunakan untuk mengatasi perbedaan karakteristik pada pasut di tempat yang berbeda. GPS dapat digunakan di kapal/perahu bersamaan dengan dilakukannya pemeruman. Pengamatan dengan menggunakan GPS bertujuan untuk penentuan posisi baik secara horizontal maupun vertikal dengan ketelitian mencapai milimeter. Untuk mencapai ketelitian yang tinggi menggunakan GPS, dapat digunakan metode kinematik diferensial baik secara real-time kinematic (RTK) maupun post- processed kinematic (PPK). Dalam beberapa kasus biasa digunakan Differential GPS (DGPS).

Penelitian ini dilakukan dengan tujuan untuk mengetahui perbedaan yang terdapat pada nilai tinggi muka air laut hasil dari data pengamatan pasut menggunakan GPS dan hasil dari data co-tidal. Untuk mengetahui perbedaan dari kedua data tersebut, maka penelitian ini harus dilakukan di tempat yang sama dengan jangka waktu yang relatif sama juga. Dengan mengetahui perbedaan yang terdapat pada nilai tinggi muka air laut hasil dari pengamatan pasut menggunakan GPS dan hasil dari co-tidal terhadap data pengamatan rambu pasut, dapat ditarik kesimpulan mengenai data pengamatan mana yang memiliki kesalahan akurasi paling kecil.

\section{METODE}

\section{Lokasi Penelitian}

Lokasi penelitian ini mengambil studi kasus wilayah Perairan Laut Jawa yang berada pada koordinat $2^{\circ} 27^{\prime} 35,21^{\prime \prime}-8^{\circ} 23^{\prime} 0,26^{\prime \prime}$ LS dan $105^{\circ} 49^{\prime} 9,76^{\prime \prime}$ $119^{\circ} 41^{\prime} 44^{\prime \prime}$ BT.

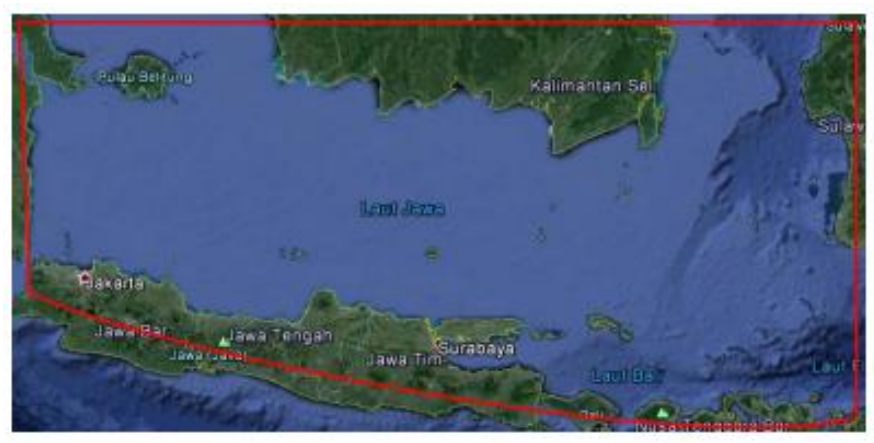

Gambar 1. Lokasi Penelitian

\section{Data dan Peralatan}

Data yang digunakan dalam penelitian ini merupakan data primer dan data sekunder dengan rincian sebagai berikut:

a. Data pengamatan pasut GPS menggunakan kapal yang bergerak di daerah perairan Laut Jawa pada tanggal 26-28 April 2018.

b. Data pengamatan pasut menggunakan rambu pasut pada tanggal $26-28$ April 2018

c. Data model geoid (EGM2008).

d. Data garis pantai di perairan Laut Jawa (GSHHG).

e. Data pengamatan dari 25 stasiun pasang surut di perairan Laut Jawa selama 1 bulan pada tanggal 1 Februari - 1 Maret 2018. 
Adapun peralatan yang digunakan dalam penelitan ini adalah berupa perangkat lunak pengolah data, antara lain:
a. RTKLIB digunakan untuk pengolahan data GPS.
b. Alltrans EGM2008 Calculator 1.2 digunakan untuk pengolahan data EGM2008.
c. Matlab R2014a digunakan untuk pengolahan data pasang surut.
d. PydroGIS 18.4 digunakan untuk pembuatan model pasang surut dan co- tidal.
e. ArcGIS 10.3 digunakan untuk overlay dan layouting hasil pengolahan data.

\section{Tahapan Pengolahan Data}

Adapun tahapan pengolahan data yang dilakukan adalah sebagai berikut:

a. Pengolahan Data Pasut GPS

Data pengamatan pasut GPS digunakan untuk memperoleh tinggi muka air laut. Dimana, tinggi muka air laut yang dihasilkan dari data ini masih mengacu pada ellipsoid. Data model geoid EGM2008 digunakan untuk koreksi tinggi muka air laut yang masih mengacu pada ellipsoid menjadi tinggi muka air laut yang mengacu pada geoid (diasumsikan berhimpit dengan MSL).

b. Pengolahan Model Pasut dan Co-tidal

Data 25 stasiun pasut dan data garis pantai digunakan untuk membuat model pasut. Metode pembuatan model pasut tersebut adalah dengan menggunkan metode interpolasi triangulasi. Hasil model pasut yang didapatkan kemudian dieksport untuk diolah menjadi co-tidal dan untuk memperoleh nilai tinggi muka air laut yang telah bereferensi pada MSL.

c. Analisis Perbandingan Nilai Pengamatan Pasut GPS dan Co-tidal terhadap Pengamatan Rambu Pasut.

Data pengamatan rambu pasut digunakan sebagai data pembanding terhadap nilai tinggi muka air laut hasil GPS dan co-tidal. Analisis yang dilakukan adalah dengan membandingkan tingkat akurasi dari perbandingan 2 nilai tinggi muka air laut (GPS dengan rambu pasut dan co-tidal dengan rambu pasut). Uji tingkat akurasi tersebut dilakukan dengan melakukan perhitungan Root Mean Square Error (RMSE).

\section{HASIL DAN PEMBAHASAN}

\section{Hasil dan Analisis Pengamatan Pasut GPS}

Hasil dari pengamatan pasut GPS menunjukkan tanggal dan waktu pengamatan GPS, tinggi ellipsoid, nilai undulasi, serta tinggi orthometrik. Waktu pengamatan GPS untuk setiap harinya berbeda-beda. Hal itu disebabkan oleh kondisi jadwal pengukuran yang kondisional. Rata-rata waktu pengamatan GPS untuk setiap harinya adalah selama 5-6 jam dengan interval pengamatan setiap 10 detik.

Tinggi ellipsoid didapatkan dari ukuran tinggi antena GPS diatas kapal/perahu sampai ke bidang ellipsoid. Kapal/perahu yang bergerak dengan adanya efek roll, pitch, dan yaw diabaikan dengan asumsi kapal bergerak dengan keadaan tenang. Data tinggi ellipsoid yang didapatkan terjadi kekosongan pada kisaran jam 11 sampai dengan jam 1 siang dikarenakan waktu istirahat dan pengamatan GPS harus diberhentikan. Sehingga, kekosongan data tersebut harus diinterpolasi agar dapat dibandingkan dengan data lainnya. Data tinggi ellipsoid ini masih mempunyai noise yang nantinya harus dibersihkan agar pola grafik yang dihasilkan menjadi baik.

Nilai undulasi yang didapatkan digunakan untuk mengkoreksi tinggi ellipsoid agar mengacu pada tinggi orthometrik (geoid). Nilai undulasi diperoleh dengan memasukkan koordinat pada setiap tinggi ellipsoid yang ada dan dihitung dengan model geoid. Model geoid yang digunakan adalah EGM2008 dengan ukuran grid sebesar 1x1 menit. Dari hasil perhitungan model geoid tersebut didapatkan nilai undulasi di setiap koordinat tinggi ellipsoid.

Tinggi orthometrik merupakan hasil akhir dari pengamatan GPS yang mengacu pada geoid. Dimana, tinggi terhadap geoid diasumsikan berhimpit dengan tinggi muka air laut rata-rata (MSL). Tinggi tersebut diperoleh dengan mengkoreksi nilai tinggi ellipsoid dengan nilai undulasi serta nilai tinggi antena GPS tehadap permukaan air laut. Sehingga, nilai akhir tinggi orthometrik tersebut adalah tinggi permukaan air laut yang mengacu pada geoid (berhimpit dengan MSL). Nilai tinggi muka air laut hasil pengamatan 
GPS tersebut ditunjukkan pada grafik pasut GPS seperti pada Gambar 2, Gambar 3, dan Gambar 4.

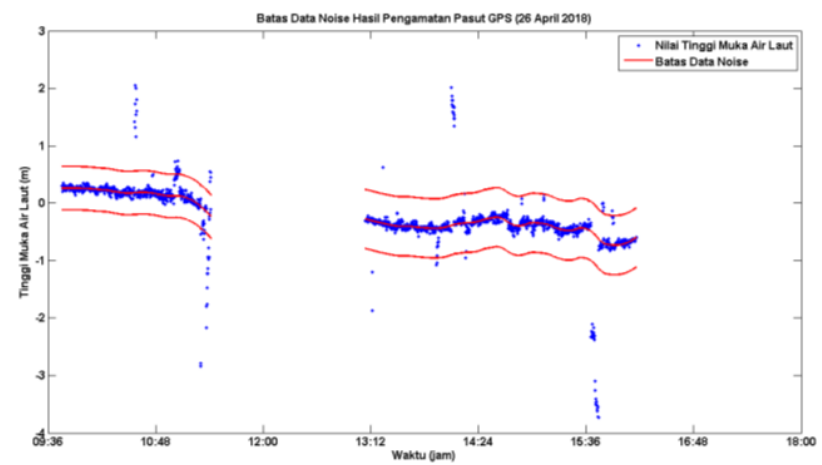

Gambar 2. Noise Pasut GPS (26 April 2018)

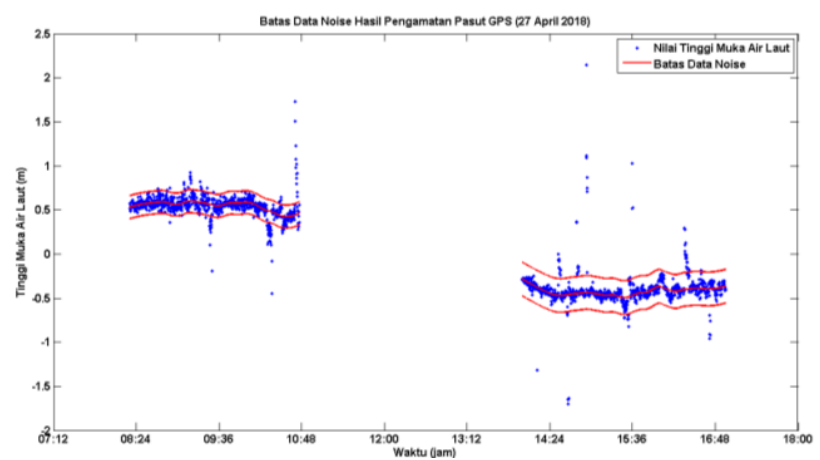

Gambar 3. Noise Pasut GPS (27 April 2018)

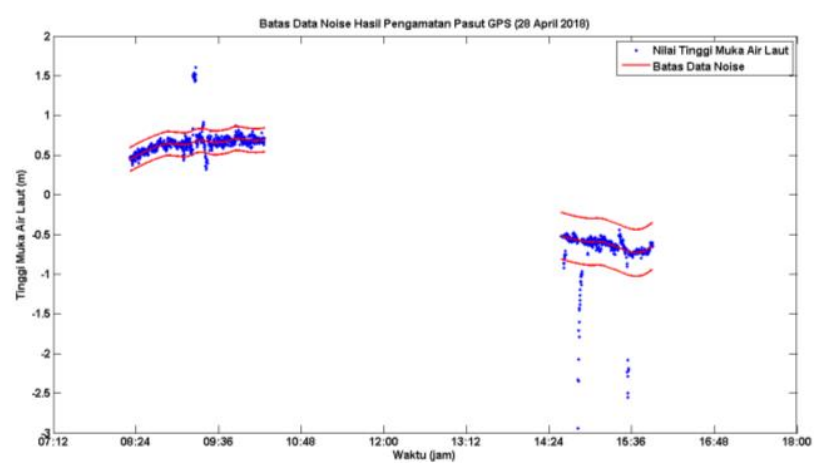

Gambar 4. Noise Pasut GPS (28 April 2018)

Gambar 2, Gambar 3, dan Gambar 4 menunjukkan grafik tinggi muka air laut pada tanggal 26, 27, dan 28 April 2018. Tinggi muka air laut tersebut sudah mengacu pada geoid (berhimpit dengan MSL) dalam satuan meter. Dari grafik tersebut terlihat data noise yang berada diluar batas atas maupun batas bawah data. Data-data yang berada diluar batas atas dan batas bawah nantinya harus dibersihkan agar diperoleh grafik smoothing pengamatan GPS yang baik. Hasil dari cleaning dan smoothing data tinggi muka air laut GPS ditunjukkan oleh grafik pada Gambar 5, Gambar 6, dan Gambar 7.
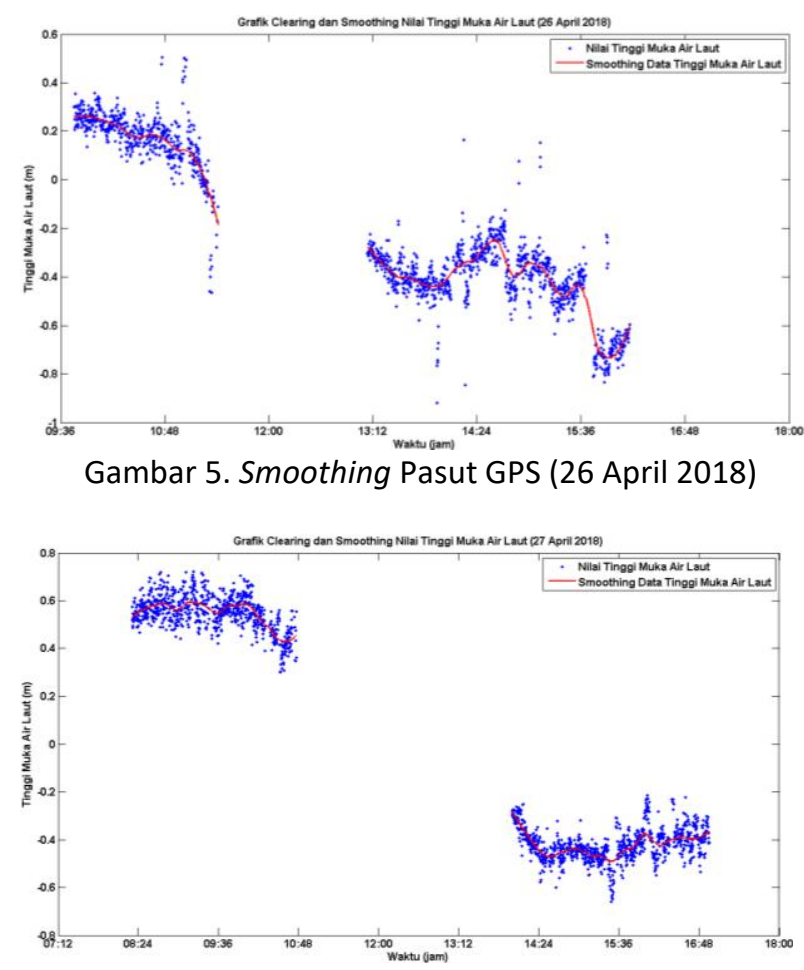

Gambar 6. Smoothing Pasut GPS (27 April 2018)

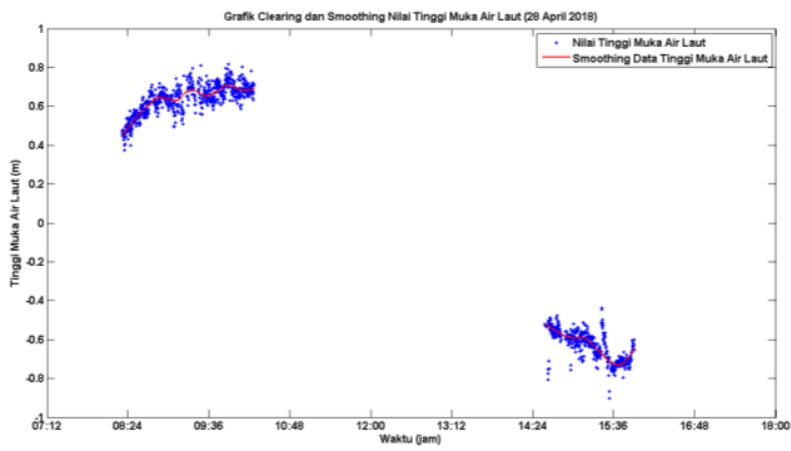

Gambar 7. Smoothing Pasut GPS (28 April 2018)

Gambar 5, Gambar 6, dan Gambar 7 menunjukkan grafik smoothing pengamatan pasut GPS pada tanggal 26, 27, dan 28 April 2018. Hasil smoothing tersebut diperoleh dari hasil clearing data pasut GPS yang masih mempunyai noise. Metode yang digunakan untuk melakukan clearing data noise dan smoothing data tersebut adalah metode moving average filtering. Proses tersebut dilakukan untuk meminimalisir adanya efek pergerakan kapal/perahu yang menyebabkan adanya data noise. Data pengamatan pasut GPS hasil smoothing ini nantinnya akan dibandingkan terhadap data hasil co-tidal dan pengamatan rambu pasut.

\section{Hasil dan Analisis Model Pasut dan Co-tidal}

Hasil model pasut yang diolah menggunakan perangkat lunak Pydro 18.4 adalah berupa kontur 
dari nilai amplitudo dan fase dari masing-masing konstanta (M2, S2, N2, K1, dan O1). Nilai masingmasing amplitudo dan fase tersebut diperoleh dengan menggunakan perhitungan least square pada perangkat lunak Matlab R2014a. Data yang digunakan adalah data pengamatan 25 stasiun pasut yang rinciannya telah disebutkan pada Sub bab Data.

Nilai amplitudo yang dihasilkan pada masing-masing konstanta menunjukkan variasi nilai pada 25 stasiun pasang surut. Nilai amplitudo terbesar untuk konstanta K1 berada pada stasiun pasut Bangka dengan nilai 0,811 meter. Nilai amplitudo terbesar untuk konstanta M2 berada pada stasiun Ketapang dengan nilai 0,477 meter. Nilai amplitudo terbesar untuk konstanta N2 berada pada stasiun pasut Ketapang dengan nilai 0,094 meter. Nilai amplitudo terbesar untuk konstanta 01 berada pada stasiun pasut Bangka dengan nilai 0,521 meter. Nilai amplitudo untuk konstanta S2 berada pada stasiun pasut Kotabaru dengan nilai 0,497 meter.

Nilai fase yang dihasilkan menunjukkan arah dan besar nilai dari perambatan gelombang konstanta dalam satuan derajat. Fase pada masing-masing konstanta harmonik merupakan fase pasang surut terhadap pasang surut setimbang di Greenwich. Variasi nilai dan arah perambatan tersebut yang menunjukkan perbedaan hasil di setiap lokasi pasang surut terhadap gaya pembangkit pasang surut. Untuk melihat perbedaan lebih jelasnya, variasi nilai dan arah pada amplitudo dan fase di setiap stasiun pasut tersebut diolah menjadi mesh (model domain) dari model pasut yang kemudian dieksport menjadi co-tidal charts.

Mesh model pasut yang dihasilkan diperoleh dari proses interpolasi data pengamatan pasut, data amplitudo dan fase konstituen pasut, serta data datum vertikal sebagai acuan nilai tinggi muka air laut. Metode interpolasi yang digunakan adalah metode triangulasi. Pada Gambar 4.7 ditunjukkan hasil dari mesh model pasut.

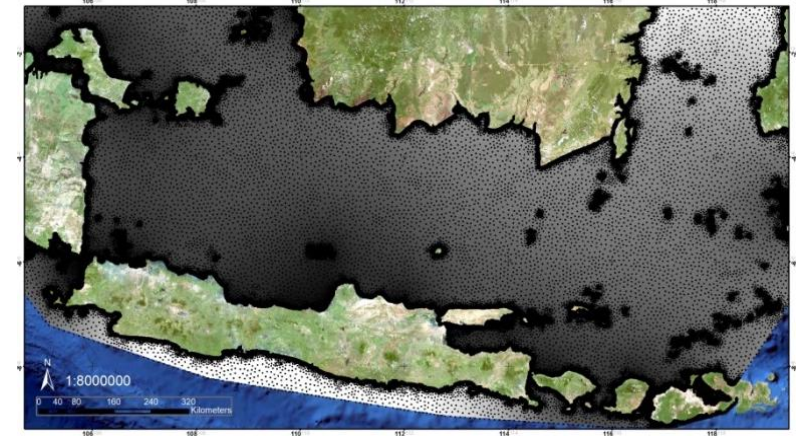

Gambar 8. Hasil Mesh Model Pasut

Metode triangulasi ini bekerja dengan membuat segitiga-segitiga yang tidak berpotongan. Dimana, untuk setiap segitiga-segitiga yang saling terhubung tersebut memiliki bobot yang berbedabeda. Nilai pembobotan yang dihasilkan pada proses interpolasi tersebut diwakilkan dengan titiktitik tengah dari segitiga-segitiga pada setiap koordinat hasil interpolasi.

Selain dapat mengeksport nilai kontur amplitudo dan fase yang kemudian diolah menjadi co-tidal chart, model pasut yang diolah dari proses pembuatan mesh (model domain) dari data pengamatan 25 stasiun pasut tersebut juga dapat dieksport untuk mengetahui nilai tinggi muka air laut. Tinggi muka air laut yang dihasilkan dapat dieksport pada koordinat tertentu sesuai kebutuhan. Datum vertikal yang digunakan juga dapat diatur sesuai kebutuhan yang diperlukan. Pada Gambar 9, Gambar 10, dan Gambar 11 ditunjukkan pola grafik tinggi muka air laut hasil cotidal.

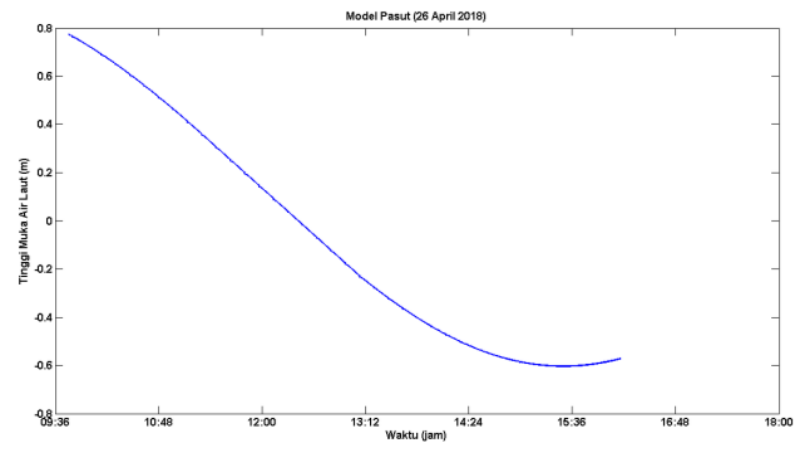

Gambar 9. Grafik Tinggi Muka Air Laut Hasil Co-tidal (26 April 2018) 


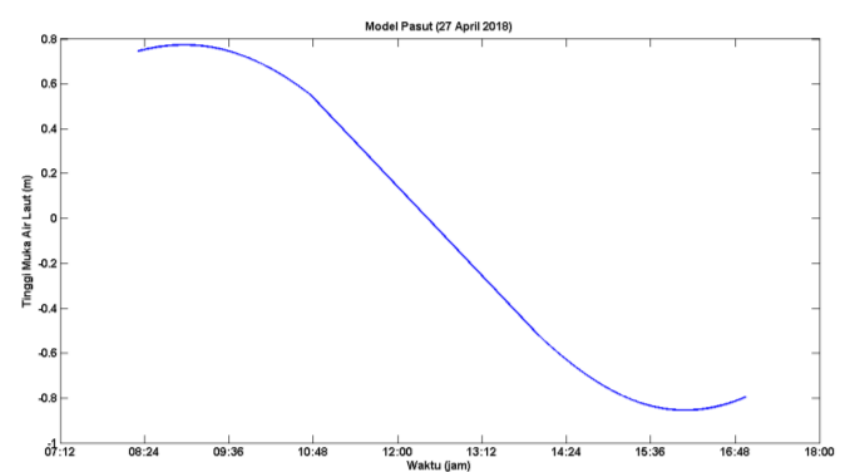

Gambar 10. Grafik Tinggi Muka Air Laut Hasil Co-tidal

(27 April 2018)

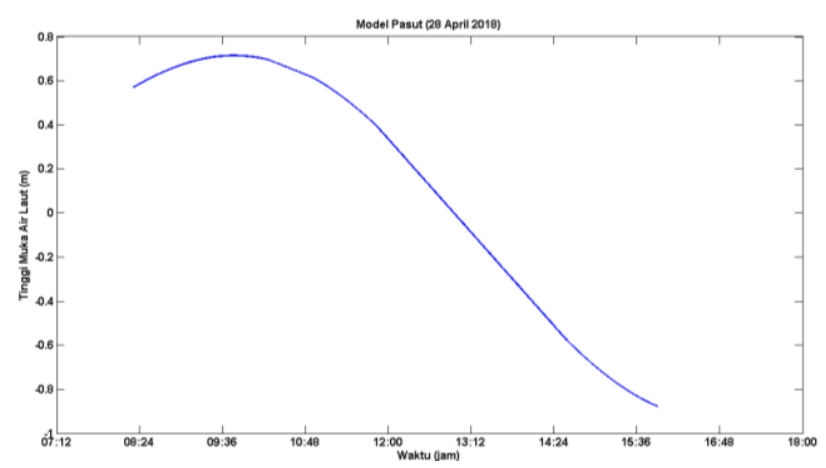

Gambar 11. Grafik Tinggi Muka Air Laut Hasil Co-tidal (28 April 2018)

Gambar 9, Gambar 10, dan Gambar 11 menunjukkan pola grafik tinggi muka air hasil cotidal pada tanggal 26, 27, dan 28 April 2018. Grafik yang ditunjukkan memiliki pola yang relatif sama dengan pola grafik tinggi muka air laut hasil smoothing GPS yang ditunjukkan pada Sub bab sebelumnya. Perbandingan pola grafik antara tinggi muka air laut hasil smoothing GPS dan cotidal terhadap tinggi muka air laut hasil pengamatan rambu pasut akan dijelaskan pada Sub bab selanjutnya.

\section{Hasil dan Analisis Perbandingan Pengamatan Pasut GPS dan Co-tidal terhadap Pengamatan Rambu Pasut}

Dalam penelitian ini, dilakukan perbandingan data tinggi muka air laut hasil dari 2 nilai pengamatan terhadap tinggi muka air laut hasil pengamatan rambu pasut. Dimana, nilai tinggi muka air laut hasil pengamatan ini diasumsikan sebagai data yang benar. Yang pertama, adalah perbandingan nilai tinggi muka air laut hasil pengamatan GPS terhadap nilai tinggi muka air laut hasil pengamatan rambu pasut. Yang kedua, adalah perbandingan nilai tinggi muka air laut hasil co-tidal (model pasut) terhadap nilai tinggi muka air laut hasil pengamatan rambu pasut.

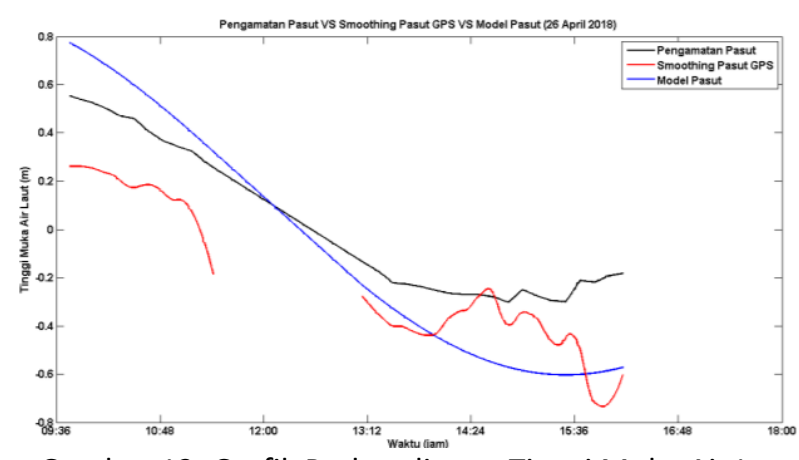

Gambar 12. Grafik Perbandingan Tinggi Muka Air Laut (26 April 2018)

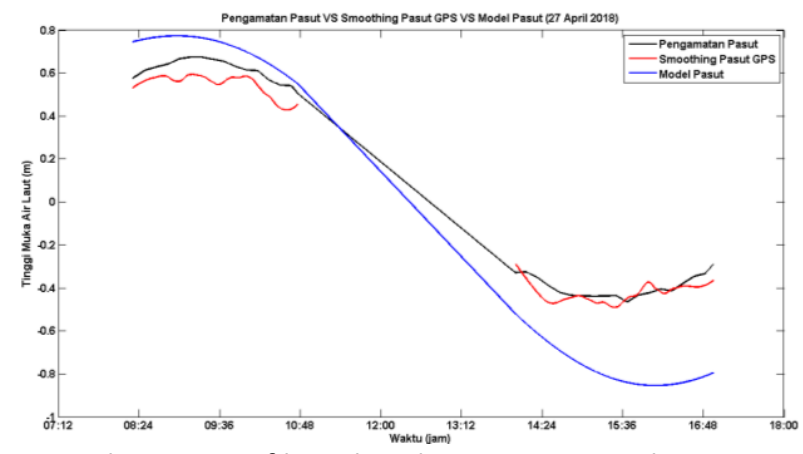

Gambar 13. Grafik Perbandingan Tinggi Muka Air Laut (27 April 2018)

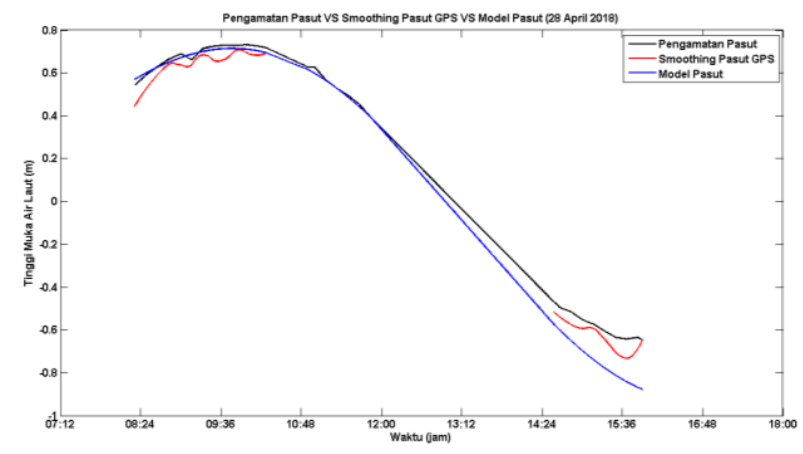

Gambar 14. Grafik Perbandingan Tinggi Muka Air Laut (28 April 2018)

Gambar 12, Gambar 13, dan Gambar 14 menunjukkan grafik perbandingan nilai tinggi muka air laut pada tanggal 26, 27, dan 28 April 2018. Grafik tinggi muka air laut hasil pengamatan GPS ditunjukkan dengan grafik berwarna merah. Grafik tinggi muka air laut hasil co-tidal (model pasut) ditunjukkan dengan grafik berwarna biru. Grafik tinggi muka air laut hasil pengamatan rambu pasut ditunjukkan dengan grafik berwarna hitam. Secara keseluruhan, pola grafik dari ketiga nilai tinggi muka air laut yang dihasilkan relatif sama namun memiliki selisih nilai tinggi muka air laut. Dalam penelitian ini, analisis tinggi muka air laut yang dilakukan dari hasil pengamatan GPS, co-tidal, dan rambu pasut adalah dengan mencari nilai tinggi 
muka air laut yang paling mendekati dengan nilai tinggi muka air laut hasil pengamatan rambu pasut yang dianggap data benar.

Analisis yang dilakukan adalah dengan menghitung tingkat akurasi pada nilai tinggi muka air laut hasil GPS dan hasil cotidal terhadap tinggi muka air laut hasil pengamatan rambu pasut. Uji tingkat akurasi dilakukan dengan menghitung nilai RMSE (Root Mean Square Error) pada masing-masing waktu pengamatan (tanggal 26, 27, dan 28 April 2018). Perhitungan RMSE dapat dilakukan dengan menggunkan rumus sebagai berikut (Ghilani dan Wolf 2011).

$$
\text { RMSE }=\sqrt{\frac{\sum_{i=1}^{n}\left(Y_{i}-\hat{y}_{i}\right)^{2}}{n}}
$$

Dimana $\sum_{i=1}^{n}\left(y_{i}-\hat{y}_{i}\right)^{2}$ merupakan jumlah kuadrat nilai ukuran dikurangi nilai yang dianggap benar, dan $n$ adalah panjang data. Dari perhitungan tersebut, didapatkan nilai RMSE yang ditunjukkan pada Tabel 1 berikut.

\begin{tabular}{|c|c|c|}
\hline Tanggal & Perbandingan & RMSE \\
\hline \multirow{2}{*}{$26 / 4 / 2018$} & $\begin{array}{l}\text { Pengamatan Rambu Pasut - } \\
\text { Pengamatan Pasut GPS }\end{array}$ & 0,246 \\
\hline & $\begin{array}{c}\text { Pengamatan Rambu Pasut - } \\
\text { Pasut Co-tidal }\end{array}$ & 0,237 \\
\hline \multirow{2}{*}{$27 / 4 / 2018$} & $\begin{array}{l}\text { Pengamatan Rambu Pasut - } \\
\text { Pengamatan Pasut GPS }\end{array}$ & 0,061 \\
\hline & $\begin{array}{c}\text { Pengamatan Rambu Pasut - } \\
\text { Pasut Co-tidal }\end{array}$ & 0,286 \\
\hline \multirow{2}{*}{$28 / 4 / 2018$} & $\begin{array}{l}\text { Pengamatan Rambu Pasut - } \\
\text { Pengamatan Pasut GPS }\end{array}$ & 0,051 \\
\hline & $\begin{array}{c}\text { Pengamatan Rambu Pasut - } \\
\text { Pasut Co-tidal }\end{array}$ & 0,109 \\
\hline
\end{tabular}

Pada perbandingan nilai tinggi muka air laut hasil rambu pasut dan hasil pasut GPS, nilai RMSE terbesar adalah pada tanggal 26 April 2018 dengan nilai 0,246 meter. Sedangkan, pada 2 hari berikutnya yaitu pada tanggal 27 dan 28 April 2018, nilai RMSE yang dihasilkan lebih kecil dengan nilai 0,061 dan 0,051 meter. Perbedaan yang dihasilkan antara tinggi muka air laut hasil rambu pasut dan hasil pasut GPS tidak selalu memberikan solusi pada level sentimeter $(\mathrm{cm})$. Ada kalanya, perbedaan nilai tinggi muka air laut yang dihasilkan akan mencapai level desimeter $(\mathrm{dm})$ sampai dengan meter $(\mathrm{m})$. Hal tersebut dapat terjadi karena beberapa faktor sebagai berikut (Mills dan Dodd 2014):
a. Kesalahan pada pengukuran tinggi stasiun base
b. Kesalahan pada pengukuran tinggi antena rover
c. Kesalahan pada model separasi.

Sedangkan, pada perbandingan nilai tinggi muka air laut hasil rambu pasut dan hasil co-tidal, nilai RMSE terbesar adalah pada tanggal 27 April 2018 dengan nilai 0,286 meter. Sementara, pada tanggal 26 dan 28 April nilai RMSE yang dihasilkan adalah sebesar 0,237 dan 0,109 meter. Dari perbandingan nilai tinggi muka air laut tersebut, baik antara hasil rambu pasut dengan GPS maupun antara hasil rambu pasut dengan co-tidal dapat diketahui bahwa pada tanggal 27 dan 28 April 2018 nilai kesalahan rata-rata pada tinggi muka air laut hasil GPS lebih kecil daripada kesalahan rata-rata hasil co-tidal. Hal tersebut dapat diartikan bahwa nilai tinggi muka air laut hasil GPS lebih mendekati terhadap nilai tinggi muka air laut hasil rambu pasut.

\section{KESIMPULAN}

Nilai tinggi muka air laut yang dihasilkan dari data pengamatan GPS adalah bereferensi terhadap ellipsoid yang kemudian dikoreksikan sehingga bereferensi pada geoid (diasumsikan berhimpit dengan MSL). Sementara, nilai tinggi muka air laut hasil dari co-tidal dan pengamatan rambu pasut bereferensi pada tinggi muka air laut rata-rata (MSL). Nilai tinggi muka air laut hasil dari data pengamatan GPS dan hasil dari co-tidal memiliki pola yang relatif sama terhadap nilai tinggi muka air laut hasil dari data pengamatan rambu pasut pada masing-masing waktu pengamatan $(26,27$, dan 28 April 2018). Berdasarkan grafik yang dihasilkan, pola yang paling mendekati adalah pada hari ketiga yaitu pada tanggal 28 April 2018.

Pada perbandingan nilai tinggi muka air laut hasil rambu pasut dan hasil pasut GPS, nilai RMSE yang didapat pada tanggal 26 April adalah sebesar 0,246 meter, tanggal 27 April sebesar 0,061 meter, dan pada tanggal 28 April sebesar 0,051 meter. Sedangkan, pada perbandingan nilai tinggi muka air laut hasil rambu pasut dan hasil cotidal, nilai RMSE pada tanggal 26 April adalah sebesar 0,237 meter, tanggal 27 April sebesar 0,286 meter, dan pada tanggal 28 April nilai RMSE yang dihasilkan adalah sebesar dan 0,109 meter. 
Dari perbandingan nilai tinggi muka air laut tersebut, baik antara hasil rambu pasut dengan GPS maupun antara hasil rambu pasut dengan cotidal dapat diketahui bahwa pada tanggal 27 dan 28 April 2018 nilai kesalahan rata-rata pada tinggi muka air laut hasil GPS lebih kecil daripada kesalahan rata-rata hasil co-tidal. Hal tersebut dapat diartikan bahwa nilai tinggi muka air laut hasil GPS lebih mendekati terhadap nilai tinggi muka air laut hasil rambu pasut.

\section{UCAPAN TERIMA KASIH}

Penulis mengucapkan terimakasih kepada Badan Informasi Geospasial yang telah menyediakan data pasang surut di 25 stasiun pasut di wilayah perairan Laut Jawa.

\section{DAFTAR PUSTAKA}

Abidin, H. Z. (2007). "Penentuan Posisi dengan GPS dan Aplikasinya", (edisi:3), Jakarta:PT. Pradnya Paramita.

Ghilani, C. D., \& Wolf, P. R. (2011). "Adjusment Computations: Spatial Data Analysis", International Journal of Geographical Information Science, (4 ed., vol. 25), Hoboken, New Jersey: John wiley and Sons, Inc.

Haryono, S., \& Narni. (2004). "Karakteristik Pasang Surut di Pulau Jawa" J. Forum Tek, vol. 28, p. 1-5.

Mills, D. J., \& Dodd. (2014). "Ellipsoidally Referenced Surveying for Hydrography", International Federation of Surveyor (FIG).

Stewart, R. H. (2008). "Introduction to Physical Oceanography", Am. J. Phys. 